\title{
Treatment of Thoracolumbar Fracture
}

\author{
Byung-Guk Kim ${ }^{1}$, Jin-Myoung Dan ${ }^{1}$, Dong-Eun Shin ${ }^{2}$ \\ ${ }^{1}$ Department of Orthopaedic Surgery, CHA Gumi Medical Center, School of Medicine, CHA University, Gumi, Korea \\ ${ }^{2}$ Department of Orthopaedic Surgery, CHA Bundang Medical Center, CHA University, Seongnam, Korea
}

The most common fractures of the spine are associated with the thoracolumbar junction. The goals of treatment of thoracolumbar fracture are leading to early mobilization and rehabilitation by restoring mechanical stability of fracture and inducing neurologic recovery, thereby enabling patients to return to the workplace. However, it is still debatable about the treatment methods. Neurologic injury should be identified by thorough physical examination for motor and sensory nerve system in order to determine the appropriate treatment. The mechanical stability of fracture also should be evaluated by plain radiographs and computed tomography. In some cases, magnetic resonance imaging is required to evaluate soft tissue injury involving neurologic structure or posterior ligament complex. Based on these physical examinations and imaging studies, fracture stability is evaluated and it is determined whether to use the conservative or operative treatment. The development of instruments have led to more interests on the operative treatment which saves mobile segments without fusion and on instrumentation through minimal invasive approach in recent years. It is still controversial for the use of these treatments because there have not been verified evidences yet. However, the morbidity of patients can be decreased and good clinical and radiologic outcomes can be achieved if the recent operative treatments are used carefully considering the fracture pattern and the injury severity.

Keywords: Thoracolumbar spine; Fracture; Treatment; Minimally invasive surgery

\section{Introduction}

Ninety percent of all spine fractures are related to the thoracolumbar region [1]. Especially, the majority of thoracolumbar injuries occur at the T11 to L2 level, which is the biomechanically weak for stress [2].

The causes of thoracolumbar fracture are different depending on patient's age. In younger patients, fracture is more likely to occur due to a high-energy trauma, such as motor vehicle accident, motorcycle accident, and falling injury. However, in elderly, even falls from standing position to ground can cause fractures due to osteoporosis and decreased cognition $[3,4]$. Twenty to forty percent of fractures are associated with neurologic injuries [5]. If the patients involve in a severe trauma, the complications, such as paralysis and deformity, may occur after that accident. Even if the patients do not experience any complications, there could be limits of daily activities or difficulty to return to work due to chronic pain [6]. Therefore, the appropriate treatment for the thoracolumbar fracture is important.

The primary goal of treatment of the thoracolumbar fracture is keeping patients alive, protecting from the further neural damage, obtaining the stability by reconstructing anatomical alignment of spinal columns and returning patients to workplace through early mobilization and rehabilitation. These fundamental principles have not been changed for decades. However, it has been ongoing

Received Aug 12, 2014; Accepted Aug 24, 2014

Corresponding author: Jin-Myoung Dan

Department of Orthopaedic Surgery, CHA Gumi Medical Center, School of Medicine, CHA University,

12 Sinsi-ro 10gil, Gumi-si, Kyungsangbuk-do, Republic of Korea

Tel: +82-54-450-9869, FAX: +82-54-450-9899, E-mail: osjmdan@gmail.com 
controversy in determining treatment methods until now.

\section{Discussion}

\section{Stability of thoracolumbar fracture}

Fracture stability is an important factor in determining the treatment of thoracolumbar fracture. Fracture stability is comprised of mechanical stability and neurological stability. Denis [7] classified instability in the thoracolumbar spine into three subgroups: mechanical instability (first degree), neurological instability (second degree), and the combined mechanical and neurologic instability (third degree).

The mechanical stability of thoracolumbar spine is evaluated by whether posterior ligament complex (PLC), which is composed of supraspinous ligament, interspinous ligament, ligametum flavum, and facet capsule, is damaged or not [8-10]. On plain radiographs, decrease of 50 percent in vertebral body height, increase of interspinous distance, and greater than 30 to 35 degrees of kyphotic deformity are suggestive of PLC injury [11-13]. Computed tomography (CT) is the most appropriate examination for assessing diastasis of facet joint, related to PLC injury [14,15]. Magnetic resonance imaging (MRI) is regarded as a significant examination in determining the treatment plan because it can evaluate PLC injury directly [16-18]. PLC injury shows high signal intensity on fat suppression T2-weighted MR images. Many studies reported that MRI has a high sensitivity and specificity for detecting PLC injury, as a result of comparing MRI findings and intraoperative findings [16-20].

Neurological symptom caused by involvement of single nerve root is classified as Frankel Grade E [21]. Except for that, the thoracolumbar fracture with complete or incomplete neurologic deficit caused by spinal canal involvement is classified as an unstable fracture regardless of the instability from fracture itself or posterior element injury. Although the fracture accompanied with neurologic injuries is not an absolute indication for operative treatment [22-25], the operative treatment is mostly performed for patients with incomplete neurologic deficit because it prevents further progression of neurologic injury, helps neurological recovery and makes early mobilization possible by achieving the stability of fracture. However, if patients have Frankel A paralysis caused by the fracture with complete neurologic injury, the neuro- logic exam should be performed again after spinal shock is over. Then, if the paralysis persists even in the second neurologic exam, it means that there is little chance of neurologic recovery resulting from surgical decompression [26]. Therefore, the goal of operative treatment is limited to not the recovery of neurologic injury but the restoration of spinal alignments and fracture stabilization $[21,27]$. On the other hand, there is a report that anterior decompression is required in order to prevent syringomyelia and maintain the proper dynamics of cerebrospinal fluid flow [28].

\section{Classification of thoracolumbar fractures}

Since the classification of thoracolumbar fractures was introduced by Boehler 75 years ago, various classification systems have been suggested until now. These classification systems have been developed to help in better communication among doctors, determining treatment plan and evaluating the prognosis.

Denis [7] proposed three column theory based on two column theory of Holdsworth [8]. He emphasized the biomechanical importance of middle column and insisted that fractures with middle column injury are unstable. Moreover, according to the fracture morphology and injury mechanisms, he classified thoracolumbar fractures into 4 categories: compression fracture, burst fracture, flexion-distraction injury (seat-belt injury), and fracturedislocation. His classification system is significant because it is simple and introduces the concept of neurological injury. However, it has also some limitations: it is difficult to distinguish stable burst fractures and unstable burst fractures [29], and its inter-observer reliability is low [30].

McAfee et al. [12] emphasized that PLC is an important structure for fracture stability, based on CT findings. Also, they subdivided the middle column injury and proposed that the middle column fails by three different forces such as axial compression, axial distraction, and translation. According to this injury mechanism, they divided thoracolumbar fractures into 6 categories: wedge compression fracture, stable burst fracture, unstable burst fracture, Chance fracture, flexion-distraction injury and translational injury. However, this classification system has not been widely used because its reliability and validity are not verified yet [29].

AO classification [31] classified thoracolumbar fractures into 3 groups, such as compression group, dis- 
traction group, and rotation group, considering injury mechanism, fracture morphology, and mechanical stability. Each group was further subdivided into subgroups of from A1 to C3. In other words, as the level of subgroup is higher and moves $\mathrm{A}$ to $\mathrm{C}$, it represents more severe degree of injury and more unstable fractures. Although this AO classification tried to suggest the comprehensive classification including all different types of fractures, it showed only moderate intraobserver and interobserver reliability due to its complexity $[29,30,32]$. This classification system could not propose the concrete definition of fracture stability and also did not include neurologic damage.

In order to overcome disadvantages of previous classification systems based on injury mechanism and fracture pattern, Vaccaro et al. [9] suggested new classification, called thoracolumbar injury severity score (TLISS). They evaluated thoracolumbar fractures using this classification based on plain radiographs, CT and/or MRI, in terms of mechanism of injury, integrity of the PLC and patient's neurologic status. In addition, these three categories for injury were subdivided and scored. The total score was determined by summing up the scores from each three categories and used to guide treatment. If the total score is 3 points, the conservative treatment is recommended. However, if it is 4 points, the conservative or operative treatment may be chosen by surgeon's preference. If that score is greater than 5 points, the operative treatment is suggested. This TLISS showed fair to substantial (kappa, 0.24-0.724) intraobserver and interobserver reliability in several studies [33-35]. However, many surgeons tended to classify the same type of injury differently because this classification classified fractures based on the mechanism of injury. To improve this drawback, Vaccaro et al. [36] proposed the modified classification, called thoracolumbar injury classification and severity score (TLCIS). In this classification, its interobserver reliability was improved by characterizing the fractures based on the fracture morphology instead of the mechanism of injury [34,37]. Oner et al. [38] insisted that this TLCIS is the most effective classification system for the treatment of thoracolumar fractures.

\section{Compression fracture}

Fifty percent of thoracolumbar fractures are compression fractures. Compression fractures are caused by axial compression alone or flexion forces and shows wedge deformities of vertebral body on radiologic examination. Middle and posterior column of spine are preserved and classified as a stable fracture. Patients with compression fractures mostly received the conservative treatment because they rarely show neurologic deficits.

As a conservative treatment, a thoracolumbosacral orthosis (TLSO) brace is applied for 8 to 12 weeks and medications are also prescribed for pain $[39,40]$. According to recent prospective randomized study [41], the outcome was better when bracing with physical therapy was performed. Severe pain is usually improved within 3 to 6 weeks. However, if the pain of fracture site is alleviated to a certain extent regardless of time period, as much as the patient can sit down without severe pain, walking is recommended wearing the brace. After that, the patient can gradually return to daily life, considering the level of pain. The prognosis of conservative treatment generally seems to be good but a small number of patients may experience persistent pain after the fracture is completely healed [4245]. These clinical outcomes are not always corresponded to radiologic ones. However, if the kyphotic angle is greater than 30 degrees or a decrease of height of vertebral body is greater than 50\%, PLC injury is suspected and the operative treatment is recommended. Additionally, if the injury is occurred in three contiguous vertebral bodies, it is also regarded as an unstable compression fracture and the operative treatment is required [46]. Usually, spinal fusion is performed as an operative treatment and in this procedure, the posterior approach is preferred than the anterior approach because most of the compression fractures do not have an involvement of the spinal canal. Short segment or long segment fusion may be chosen depending on the situation. Nowadays, satisfactory results are reported by conducting short segment instrumentation without fusion [47]. The operative treatment is also required for coronal split fractures or pincer fractures, classified as AO 2.2 or 2.3, because nonunion or pseudoarthrosis can occur due to the intrusion of disc material into the fracture site $[31,48]$. Occasionally, the anterior fusion using the anterior approach is required if there is severe bone void in the vertebral body after the fracture or the reduction is needed due to old fractures.

\section{Burst fracture}

A burst fracture is caused by axial compression and ac- 
companied with retropulsed bone fragments into spinal canal. Not only fracture of posterior cortex of vertebral body but also retropulsion of the fractured fragments into the spinal canal and an increase of inter-pedicular distance are presented on radiologic examinations [39]. Unlike compression fractures, neurologic injury and posterior column injury can occur more frequently. The posterior column is destroyed by compression, lateral flexion, or torsion. In addition, subluxation of the facet, displaced lamina fracture, and disruption of posterior ligament may be accompanied with it.

The indicators for treatment of burst fractures are also the mechanical and neurological stability of fractures which are mentioned earlier. The conservative treatment using orthosis is mostly recommended for stable burst fractures but the operative treatment is required for unstable burst fractures.

\section{1) Nonoperative treatment}

The conservative treatment for burst fractures is performed based on physical examinations and imaging studies. In radiologic studies, more than $50 \%$ decrease of vertebral body and less than 30 degrees of traumatic kyphosis are regarded as mechanically stable findings for the conservative treatment [49,50]. MRI is used to evaluate PLC injury and has high sensitivity and specificity. In many studies, the operative treatment was conducted if there was PLC injury on MRI. However, according to the prospective study by Alanay et al. [51], although there was not PLC injury, PLC could not prevent the loss of fracture reduction when the fracture was treated by cast immobilization after the reduction of burst fracture. Therefore, even though PLC injury is not observed, the conservative treatment should be performed when it is considered that there is no instability taking into account plain radiographs and CT findings.

When there is the neurologic injury, treatment should be performed considering the location of fracture and the retropulsed bone fragments into the spinal canal. While less than $40 \%$ of canal narrowing can cause neurologic injury at upper thoracic level, more than $90 \%$ of canal narrowing may not cause it at lower lumbar level [52-54]. As the retropulsed bone fragments into the spinal canal are larger, the chance of neurologic injury can be more common $[55,56]$. However, the size of this retropulsed bone fragment is rarely related to the severity of neurological injury. Thus, if burst fractures are not accompanied with neurological injury, the spinal canal involvement of fractured fragments itself cannot be the indication for surgical decompression [39]. It is because the degree of spinal canal involvement on imaging studies, which is taken after injury, is not able to reflect the impact on nerves at the time of injury [57] and also remodeling of the spinal canal may occur as time passes after either conservative or operative treatment is completed. Dai [58] reported that there is no difference in the canal remodeling between the conservative and the operative treatment. As Mumford et al. [59] reported, the canal remodeling occurred with the conservative treatment even though nearly $66 \%$ of spinal canal was involved. The remodeling was completed within one year in most cases. Accordingly, the conservative treatment can be used for burst fractures without neurologic compromise regardless of degree of spinal canal involvement of fracture fragments if there is any progressive neurologic deficit. According to prior studies, when burst fractures without neurologic symptoms were treated by the conservative treatment, functional outcomes were not different from those of the operative treatment. They reported that the conservative treatment was even better in terms of cost and complications [60-63].

Therefore, the conservative treatment should be considered first in managing mechanically and neurologically stable burst fractures. Tezer et al. [42] described that the conservative treatment is appropriate for patients who do not have neurologic deficit and PLC injury and have less than $50 \%$ of the vertebral height loss and less than 25 degrees of traumatic kyphosis.

In the conservative treatment, hyperextension cast or TLSO is applied for 8 to 12 weeks, considering patient's pain. Wood et al. [64] reported that there was no difference in the results of treatment of burst fractures without neurological injury between cast and orthosis treatment. Also, Cantor et al. [50] and Tropiano et al. [65] reported that they could achieve satisfactory results by early ambulation wearing cast or TLSO. Long-term bed rest may cause embolization, pressure ulcer and pulmonary complication, and exacerbate patient's general condition. Thus, it is suggested to start the early ambulation as much as possible. If the patient starts the ambulation after wearing cast or orthosis, follow-up standing radiographs are required 1 to 2 weeks later. In most patients, kyphosis of fractures progresses over time and frequently returns to the degree of kyphosis at the time of injury. However, this 
is not associated with patients' clinical manifestation. The conservative treatment can be continued if there are no greater than 10 degrees of obvious increase of kyphotic angle or the pain during the conservative treatment [66].

\section{2) Operative treatment}

The operative treatment for burst fractures is generally performed when there is neurological or mechanical instability and its goal is decompression of spinal canal and nerve root for neurological recovery, restoration and maintenance of vertebral height and spinal alignment, rigid fixation for early ambulation and rehabilitation, and prevention of progressive neurological injury and kyphotic deformity. It is controversial depending on the degree of fracture and neurological injury but the surgery is generally conducted with posterior, anterior or anteriorposterior approaches.

\section{(1) Anterior approach}

If nerve compression due to disc or fractured fragments was shown on imaging studies in burst fractures with incomplete neurologic injury, it can be an indication for anterior decompression. The nerve compression in burst fractures usually occurs in anterior aspect of the spinal canal due to retropulsion of fracture fragments. Thus, anterior decompression is superior to remove the fragments or soft tissues which compress the neural structures. After this anterior decompression is completed, the anterior reconstruction is performed using plate or rod with bone graft. Kaneda et al. [67] treated 150 patients with thoracolumbar burst fractures and neurological deficits by anterior decompression and fusion, and followed up them for 8 years. As a result of it, they reported $93 \%$ of fusion rate and $72 \%$ of complete recovery of bladder function. In addition, $95 \%$ of patients showed neurologic recovery more than Frankel Grade 1. The anterior approach not only decompresses the neural contents more efficiently and but also provides the superior mechanical stability. Hitchon et al. [68] reported that the anterior approach was more advantageous in the correction and the maintenance of each deformity than the posterior approach. Sasso et al. [69] also reported that the average of sagittal plane correction was $8.1^{\circ}$ with the anterior approach but it was $1.8^{\circ}$ with the posterior approach. In some biomechanical studies, anterior approach offered superior mechanical stability than the posterior approach [70,71]. Therefore, the reconstruction of vertebral body with the anterior approach can be used to minimize the loss of motion segment and achieve the rigid fixation if the patient has neurological injury or the loss of anterior support due to severe comminution of the vertebral body. However, the anterior approach has some disadvantages: it may result in visceral injury and it is an unfamiliar approach to many surgeons. Also, there is the risk of bleeding and pulmonary complications. For these disadvantages, it is less commonly used than the posterior approach.

\section{(2) Posterior approach}

Posterior approach is usually used for the treatment of burst fractures without neurologic deficit. However, even though there is neurological injury, posterior approach can be used for the purpose of the decompression of the spinal canal depending on the mechanism or the pattern of fracture. The decompression can be achieved by indirect reduction using ligamentotaxis or direct decompression (Fig. 1). The reduction using ligamentotaxis is successful if it is completed within 3 days after the injury [40]. The increase of vertebral canal after the indirect reduction is averagely less than $20 \%$ but may sometimes increase up to $50 \%$ depending on situation $[64,72,73]$. However, if the canal encroachment of bone fragments is greater than $67 \%$, it is not effective because annulus is destroyed in many cases [74]. If the surgery is delayed or the indirect decompression is difficult due to severe canal compromise, the direct reduction [75] with the transpedicular approach or direct decompression [76] with laminectomy can be performed.

The pedicle screw fixation is the most commonly used for the fixation of fractures with the posterior approach. This pedicle screw has an advantage of being able to fix three columns of spine. Due to the development of instruments, strength of the screws is improved and the use of short segment fixation, which fixes the above and below segment of fracture site, has been increasing. However, there were studies that the failure rate of this short segment fixation was $20 \%$ to $50 \%$ and the loss of reduction was $50 \%$ to $90 \%$ [77-80]. McCormack et al. [81] suggested load sharing classification (LSC) in order to predict the prognosis of short segment fixation using posterior approach. This classification divided spine fractures into 3 categories according to the amount of damaged vertebral body, the spread of the fragments in the fracture site and the amount of corrected traumatic kyphosis; then, each category was scored from 1 to 3 according to 
the degree. When the total score is more than 6 points, they insisted that the long segment fixation, which fixes at least more than two segments of above and below the
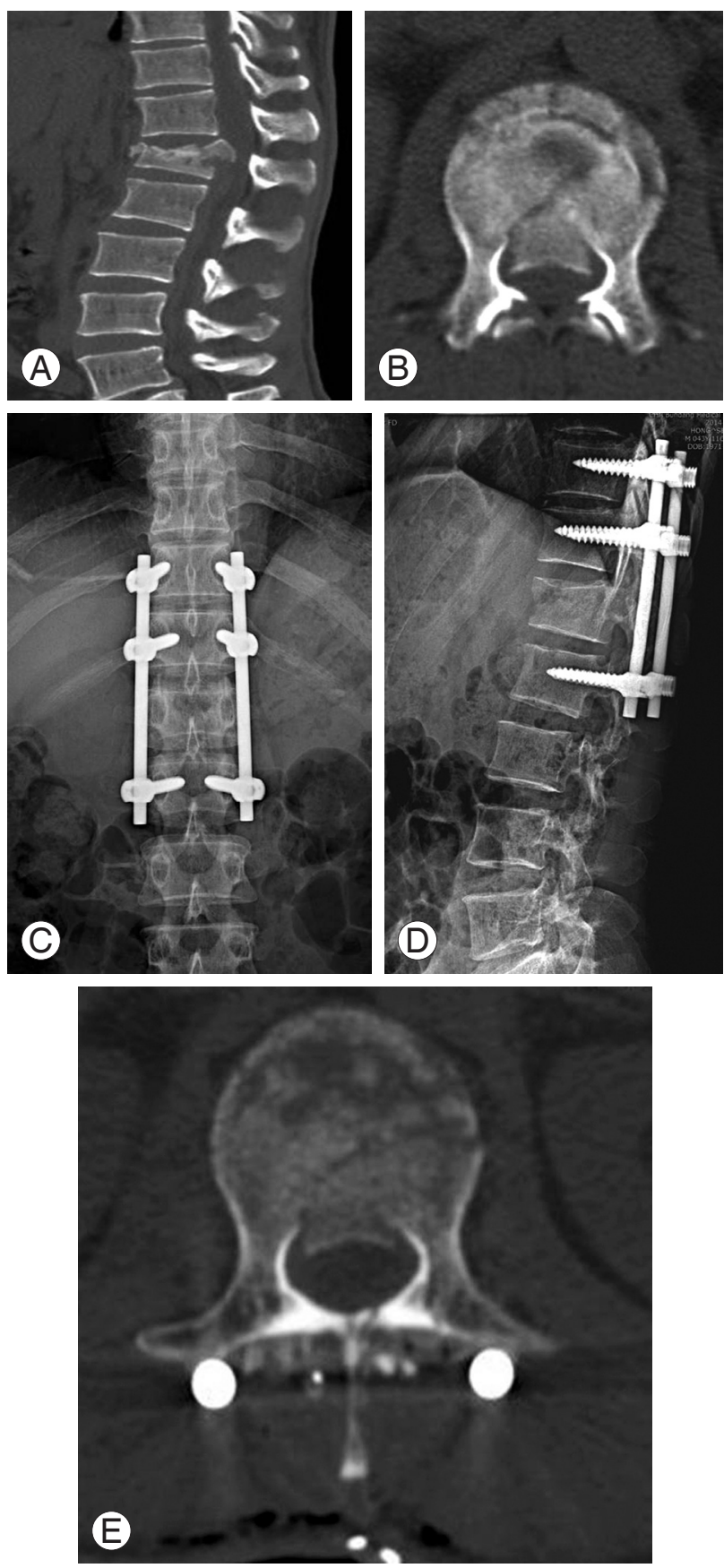

Fig. 1. A 42-year-old male patient with falling injury. Conus medullaris syndrome was diagnosed with symptoms including loss of perianal sensation, bladder and bowel dysfunction at the time of injury. (A) Burst fractures at L1 on sagittal computed tomography (CT) scan at the time of injury. (B) Around $50 \%$ of canal involvement by retropulsed bony fragments on axial CT scan at the time of injury. (C, D) Plain radiographs after indirect reduction and instrumented fusion with posterior approach. (E) Postoperative axial CT scans showing canal decompression by indirect reduction. fracture site, or the anterior reconstruction with the anterior approach are required.

The posterior short segment fixation can be performed by open or percutaneous method and supported by transpedicular cancellous bone grafting, vertebroplasty [82-84] using calcium sulfate, polymethyl methacrylate or kyphoplasty [85-88] using calciumphosphate for anterior structural support. The transpedicular cancellous bone grafting showed successful results in short-term followup but, in long-term follow-up, there was no difference from the short segment fixation without bone graft and it could not prevent the loss of reduction and the failure of instruments [89,90]. However, Toyone et al. [91,92] reported that there was no reduction loss and degenerative change in disc of adjacent segment in their 10year follow-up using hydroxyapatite ceramic instead of cancellous bone grafting. Verlaan et al. [88] described that posterior short segment fixation with kyphoplasty is a feasible and safe treatment based on their 6-year follow-up results of 20 patients who have burst fracture with $\mathrm{AO}$ type $\mathrm{A} 3$ or $\mathrm{B} 2$ type, LSC scoring equal or higher than 6 points and without neurologic deficit. Additionally, inserting additional pedicle screws at the level of the fracture site can help to provide better kyphosis correction with saving motion segments and offers improved biomechanical stability $[82,93,94]$.

The fixation of burst fractures by posterior approach is generally conducted with posterolateral fusion or posterior fusion. However, Dai et al. [95] and Ni et al. [96] reported good results by using open or percutaneous pedicle screw fixation only without fusion in patients who have the thoracolumbar burst fractures with LSC scoring equal to or less than 6 points.

\section{(3) Combined anterior-posterior approach}

Combined anterior-posterior approach can be indicated when PLC injury is accompanied with incomplete neurological injury due to canal encroachment of fracture fragments or neurological symptoms persist after the surgery using posterior approach or fixed kyphotic deformities occur more than two weeks after the injury [97]. The fixation with anterior-posterior approach can provide more improved stability for all range of motion in spine, comparing to the fixation with anterior or posterior approach alone [98]. However, this approach has more bleeding risk and longer operation time, in addition, it has not been proven yet that the clinical and 
radiological outcomes of this approach is more superior than the fixation with anterior or posterior approach alone [99]. Nowadays, the interbody fusion using posterior approach has been developed and used to stabilize the vertebral body, instead of Anterior-Posterior approach $[100,101]$.

\section{Flexion-distraction injury}

Flexion-distraction injury, or so-called Chance injury, occurs by primary distractive forces on the spine. The axis of rotation is located within or in front of anterior vertebral body. Thus, the distractive forces are loaded on a posterior column and a middle column, and distractive or compressive forces are loaded on an anterior column. This injury generally occurs in high energy motor vehicle accident when wearing only lap belt without shoulder belt. Abdominal injuries are also accompanied with 30\% of those patients. It accounts for $1 \%$ to $16 \%$ of all thoracolumbar fractures and occur most commonly in the thoracolumbar junction. The neurological injury is found in $25 \%$ of patients $[102,103]$. If only bone injury occurs without ligament injury, it is unstable during the acute phase but it will be stabilized with bone union as time elapsed. Thus, the brace treatment is possible if only bony structure is damaged without displacement. However, if PLC was disrupted, the conservative treatment is not recommended because progression of kyphosis, nonunion, or exacerbation of neurologic condition may be induced [104] (Fig. 2). PLC injury may be missed because the displacement of posterior structure caused by distraction force at the time of injury can be reduced spontaneously. In this case, PLC injury should be suspected by confirming swelling or tenderness on spinous process and evaluate more precisely using MRI.

Fusion with posterior instrumentation is preferred in most cases as the operative treatment. This operative method providing compressive and tension band effect resists effectively to the distractive forces. The vertebral body is not seriously damaged in flexion-distraction injury; thus, it is mostly treated by the short segment fixation.

However, recently, only posterior instrumentation without fusion is often used for the treatment. Because there is no fusion process, it can be conducted by percutaneous screw fixation. Kim et al. [105] performed open short segment pedicle screw fixation to 11 patients who have flexion-distraction injury without neurological injury and reported satisfactory sagittal alignments in more than 18 months follow-up. Grossbach et al. [106] compared and analyzed the clinical and radiological outcomes between open posterior instrumentation with posterolateral fusion group and percutaneous pedicle screw fixation group. As a result of it, they reported that percutaneous method was effective as like open method.
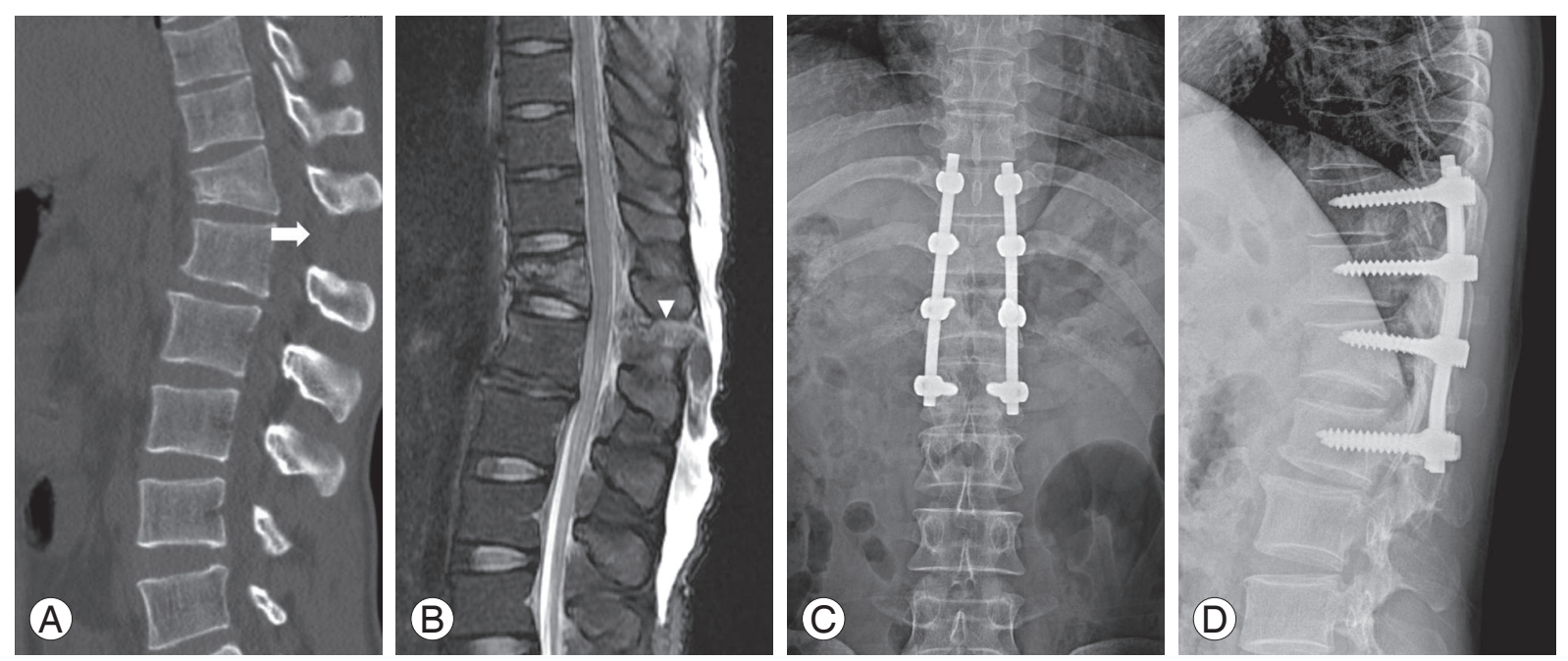

Fig. 2. A 31 -year-old male patient who sustained seat belt injury from motor vehicle accident. (A) A wedge deformity at T12 and an increased interspinous distance on sagittal computed tomography scan (arrow). (B) Posterior ligament complex injury on T2 fat suppression sagittal magnetic resonance imaging (arrow head). (C, D) Anteroposterior and lateral radiograph images of flexion distraction injury after the indirect reduction and posterior instrumented fusion using the posterior approach. 


\section{Fracture-dislocation injury}

Fracture-dislocation injury in thoracolumbar region is caused by various combinations of shear, torsion, distraction, flexion and extension forces and is very unstable injury because three columns, including anterior, middle and posterior column, are damaged. This is a high energy injury and $75 \%$ of it is accompanied with neurological injury [107]. The conservative treatment is not recommended for it because there are not only fractures but also various degrees of ligament and disc injury. It would be diagnosed if there is unilateral or bilateral facet fracture, subluxation or dislocation. If there is only subtle facet subluxation without neurological injury, it requires more attention for diagnosis. Lateral translation and anteroposterior translation of spine may be observed by anteroposterior radiographs and lateral radiographs, respectively. CT is useful for the evaluation for bone injury and facet. MRI is used for determining the degree of disc, ligament and spinal canal injury.

Mostly, the reduction and the instrumented fusion using posterior approach are prefered for this injury. Although the anterior approach is rarely used, if anterior column support is not enough or canal decompression is required after posterior sugery, the interbody fusion [108] using posterior approach or the anterior reconstruction can be performed [66] (Fig. 3).
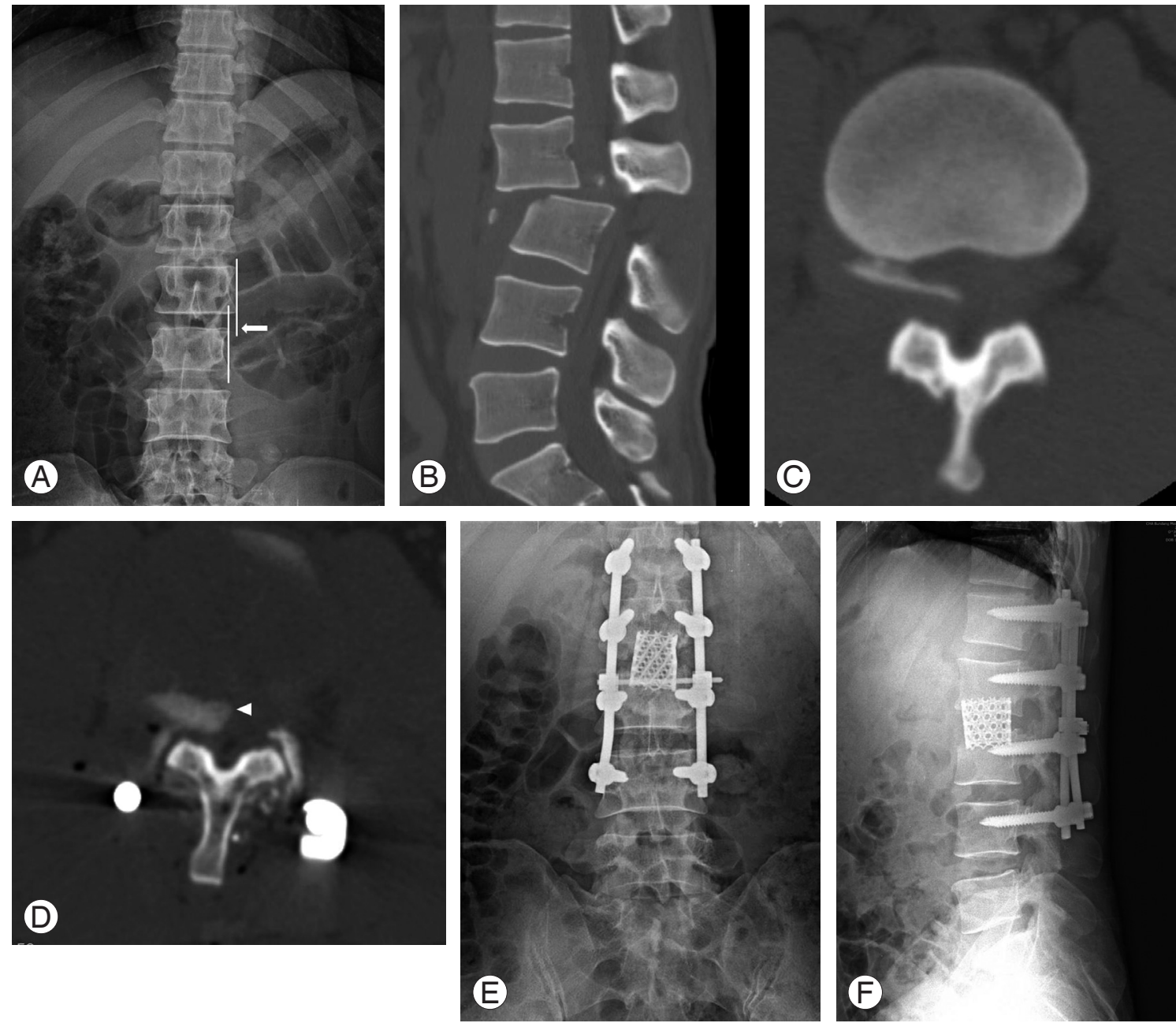

Fig. 3. A 47-year-old male patient with fracture-dislocation injury. (A) Lateral translation of $L 3$ compared to $L 2$ on anteroposterior radiographs (arrow) right after the injury. (B) Posterior translation of L3 to L2 on sagittal computed tomography (CT) scan right after the injury. (C) Bony fragment within the spinal canal on preoperative axial CT scan. (D) Bony fragments were not reduced after the reduction and posterior instrumented fusion (arrow head). (E, F) Anteroposterior and lateral radiographs after removal of bony fragments and fusion with cages through the anterior approach. 


\section{Conclusions}

Thoracolumbar fractures have been classified into compression fracture, burst fracture, flexion-distraction injury and fracture-dislocation injury, depending on injury mechanism and fracture morphology. Each injury is also subdivided into stable fracture and unstable fracture, according to the presence of neurologic injury, soft tissue injury and bone injury. The conservative treatment is recommended for stable fractures but the operative treatment is needed for unstable fractures. In radiologic studies, more than $50 \%$ of vertebral body height loss, more than 30 degrees of traumatic kyphosis, more than $50 \%$ of canal enchroachment, facet fracture, subluxation or dislocation are regarded as unstable findings; in addition, PLC injury is also regarded as an unstable finding on MRI. Abnormal findings in neurologic examinations at the time of injury also imply the spinal instability. By the evaluation of the stability of spinal column based on detailed physical examinations and imaging studies, if it is unstable, the operative treatment using anterior, posterior or combined anterior-posterior approach is performed. For the operative treatment, the instrumented fusion has been conventionally performed following the fracture reduction; however, according to fracture patterns and degrees, posterior instrumentation without fusion following indirect reduction have been increasing in recent years. The instrumentation can be achieved through percutaneous fixation. The requirement for the operative treatment using anterior approach has been decreased along with the development of pedicle screws and posterior operation techniques for canal decompression and anterior reconstruction such as transpedicular bone graft, cement augmentation or interbody fusion. The principals which obtain mechanical and neurological stability of spine have not been changed, however, the surgical methods have been diversified. Accordingly, the surgeons should make sure of the indications, advantages and disadvantages of each operative treatment in determining the treatment plan.

\section{Conflict of Interest}

No potential conflict of interest relevant to this article was reported

\section{References}

1. DeWald RL. Burst fractures of the thoracic and lumbar spine. Clin Orthop Relat Res 1984;(189):150-61.

2. Gertzbein SD. Scoliosis Research Society. Multicenter spine fracture study. Spine (Phila Pa 1976) 1992;17: 528-40.

3. Rockwood CA, Green DP, Bucholz RW. Rockwood and Green's fractures in adults. Philadelphia: Lippincott Williams \& Wilkins; 2006.

4. Kim DH, Silber JS, Albert TJ. Osteoporotic vertebral compression fractures. Instr Course Lect 2003;52: 541-50.

5. Hsu JM, Joseph T, Ellis AM. Thoracolumbar fracture in blunt trauma patients: guidelines for diagnosis and imaging. Injury 2003;34:426-33.

6. McLain RF. Functional outcomes after surgery for spinal fractures: return to work and activity. Spine (Phila Pa 1976) 2004;29:470-7.

7. Denis F. The three column spine and its significance in the classification of acute thoracolumbar spinal injuries. Spine (Phila Pa 1976) 1983;8:817-31.

8. Holdsworth F. Fractures, dislocations, and fracturedislocations of the spine. J Bone Joint Surg Am 1970;52:1534-51.

9. Vaccaro AR, Zeiller SC, Hulbert RJ, et al. The thoracolumbar injury severity score: a proposed treatment algorithm. J Spinal Disord Tech 2005;18:209-15.

10. Terk MR, Hume-Neal M, Fraipont M, Ahmadi J, Colletti PM. Injury of the posterior ligament complex in patients with acute spinal trauma: evaluation by MR imaging. AJR Am J Roentgenol 1997;168:1481-6.

11. Benson DR, Burkus JK, Montesano PX, Sutherland TB, McLain RF. Unstable thoracolumbar and lumbar burst fractures treated with the $\mathrm{AO}$ fixateur interne. J Spinal Disord 1992;5:335-43.

12. McAfee PC, Yuan HA, Fredrickson BE, Lubicky JP. The value of computed tomography in thoracolumbar fractures. An analysis of one hundred consecutive cases and a new classification. J Bone Joint Surg Am 1983;65:461-73.

13. Reid DC, Hu R, Davis LA, Saboe LA. The nonoperative treatment of burst fractures of the thoracolumbar junction. J Trauma 1988;28:1188-94.

14. Schweitzer KM, Vaccaro AR, Harrop JS, et al. Interrater reliability of identifying indicators of posterior ligamentous complex disruption when plain films are 
indeterminate in thoracolumbar injuries. J Orthop Sci 2007;12:437-42.

15. Lee JY, Vaccaro AR, Schweitzer KM Jr, et al. Assessment of injury to the thoracolumbar posterior ligamentous complex in the setting of normal-appearing plain radiography. Spine J 2007;7:422-7.

16. Brightman RP, Miller CA, Rea GL, Chakeres DW, Hunt WE. Magnetic resonance imaging of trauma to the thoracic and lumbar spine. The importance of the posterior longitudinal ligament. Spine (Phila Pa 1976) 1992;17:541-50.

17. Emery SE, Pathria MN, Wilber RG, Masaryk T, Bohlman $\mathrm{HH}$. Magnetic resonance imaging of posttraumatic spinal ligament injury. J Spinal Disord 1989;2:229-33.

18. Petersilge CA, Pathria MN, Emery SE, Masaryk TJ. Thoracolumbar burst fractures: evaluation with MR imaging. Radiology 1995;194:49-54.

19. Lee HM, Kim HS, Kim DJ, Suk KS, Park JO, Kim $\mathrm{NH}$. Reliability of magnetic resonance imaging in detecting posterior ligament complex injury in thoracolumbar spinal fractures. Spine (Phila Pa 1976) 2000;25:2079-84.

20. Haba H, Taneichi H, Kotani Y, et al. Diagnostic accuracy of magnetic resonance imaging for detecting posterior ligamentous complex injury associated with thoracic and lumbar fractures. J Neurosurg 2003;99:20-6.

21. Vaccaro AR, Lim MR, Hurlbert RJ, et al. Surgical decision making for unstable thoracolumbar spine injuries: results of a consensus panel review by the Spine Trauma Study Group. J Spinal Disord Tech 2006;19:1-10.

22. Andreychik DA, Alander DH, Senica KM, Stauffer ES. Burst fractures of the second through fifth lumbar vertebrae. Clinical and radiographic results. J Bone Joint Surg Am 1996;78:1156-66.

23. Dai LY, Jiang LS, Jiang SD. Conservative treatment of thoracolumbar burst fractures: a long-term follow-up results with special reference to the load sharing classification. Spine (Phila Pa 1976) 2008;33:2536-44.

24. Knight RQ, Stornelli DP, Chan DP, Devanny JR, Jackson KV. Comparison of operative versus nonoperative treatment of lumbar burst fractures. Clin Orthop Relat Res 1993;(293):112-21.

25. Moller A, Hasserius R, Redlund-Johnell I, Ohlin A, Karlsson MK. Nonoperatively treated burst fractures of the thoracic and lumbar spine in adults: a 23- to 41-year follow-up. Spine J 2007;7:701-7.

26. Bohlman HH, Freehafer A, Dejak J. The results of treatment of acute injuries of the upper thoracic spine with paralysis. J Bone Joint Surg Am 1985;67:360-9.

27. Pneumaticos SG, Triantafyllopoulos GK, Giannoudis PV. Advances made in the treatment of thoracolumbar fractures: current trends and future directions. Injury 2013;44:703-12.

28. Bains RS, Althausen PL, Gitlin GN, Gupta MC, Benson DR. The role of acute decompression and restoration of spinal alignment in the prevention of posttraumatic syringomyelia: case report and review of recent literature. Spine (Phila Pa 1976) 2001;26:E399402.

29. Bono CM, Vaccaro AR, Hurlbert RJ, et al. Validating a newly proposed classification system for thoracolumbar spine trauma: looking to the future of the thoracolumbar injury classification and severity score. J Orthop Trauma 2006;20:567-72.

30. Wood KB, Khanna G, Vaccaro AR, Arnold PM, Harris MB, Mehbod AA. Assessment of two thoracolumbar fracture classification systems as used by multiple surgeons. J Bone Joint Surg Am 2005;87:1423-9.

31. Magerl F, Aebi M, Gertzbein SD, Harms J, Nazarian S. A comprehensive classification of thoracic and lumbar injuries. Eur Spine J 1994;3:184-201.

32. Mirza SK, Mirza AJ, Chapman JR, Anderson PA. Classifications of thoracic and lumbar fractures: rationale and supporting data. J Am Acad Orthop Surg 2002;10:364-77.

33. Raja Rampersaud Y, Fisher C, Wilsey J, et al. Agreement between orthopedic surgeons and neurosurgeons regarding a new algorithm for the treatment of thoracolumbar injuries: a multicenter reliability study. J Spinal Disord Tech 2006;19:477-82.

34. Harrop JS, Vaccaro AR, Hurlbert RJ, et al. Intrarater and interrater reliability and validity in the assessment of the mechanism of injury and integrity of the posterior ligamentous complex: a novel injury severity scoring system for thoracolumbar injuries. Invited submission from the Joint Section Meeting On Disorders of the Spine and Peripheral Nerves, March 2005. J Neurosurg Spine 2006;4:118-22.

35. Patel AA, Vaccaro AR, Albert TJ, et al. The adoption of a new classification system: time-dependent variation in interobserver reliability of the thoracolumbar 
injury severity score classification system. Spine (Phila Pa 1976) 2007;32:E105-10.

36. Vaccaro AR, Lehman RA Jr, Hurlbert RJ, et al. A new classification of thoracolumbar injuries: the importance of injury morphology, the integrity of the posterior ligamentous complex, and neurologic status. Spine (Phila Pa 1976) 2005;30:2325-33.

37. Whang PG, Vaccaro AR, Poelstra KA, et al. The influence of fracture mechanism and morphology on the reliability and validity of two novel thoracolumbar injury classification systems. Spine (Phila Pa 1976) 2007;32:791-5.

38. Oner FC, van Gils AP, Dhert WJ, Verbout AJ. MRI findings of thoracolumbar spine fractures: a categorisation based on MRI examinations of 100 fractures. Skeletal Radiol 1999;28:433-43.

39. Canale ST, Beaty JH, Campbell WC. Campbell's operative orthopaedics. St. Louis, MO: Mosby; 2012.

40. Vaccaro AR, Kim DH, Brodke DS, et al. Diagnosis and management of thoracolumbar spine fractures. J Bone Joint Surg Am 2003;85:2456-70.

41. Stadhouder A, Buskens E, Vergroesen DA, Fidler MW, de Nies F, Oner FC. Nonoperative treatment of thoracic and lumbar spine fractures: a prospective randomized study of different treatment options. J Orthop Trauma 2009;23:588-94.

42. Tezer M, Erturer RE, Ozturk C, Ozturk I, Kuzgun U. Conservative treatment of fractures of the thoracolumbar spine. Int Orthop 2005;29:78-82.

43. Post RB, Keizer HJ, Leferink VJ, van der Sluis CK. Functional outcome 5 years after non-operative treatment of type A spinal fractures. Eur Spine J 2006;15:472-8.

44. Post RB, van der Sluis CK, Leferink VJ, Dijkstra PU, ten Duis HJ. Nonoperatively treated type A spinal fractures: mid-term versus long-term functional outcome. Int Orthop 2009;33:1055-60.

45. Butler JS, Walsh A, O'Byrne J. Functional outcome of burst fractures of the first lumbar vertebra managed surgically and conservatively. Int Orthop 2005;29:514.

46. Rea GL, Zerick WR. The treatment of thoracolumbar fractures: one point of view. J Spinal Disord 1995;8:368-82.

47. Khare S, Sharma V. Surgical outcome of posterior short segment trans-pedicle screw fixation for thoracolumbar fractures. J Orthop 2013;10:162-7.
48. De Boeck H, Opdecam P. Split coronal fractures of the lumbar spine. Treatment by posterior internal fixation and transpedicular bone grafting. Int Orthop 1999;23:87-90.

49. Krompinger WJ, Fredrickson BE, Mino DE, Yuan HA. Conservative treatment of fractures of the thoracic and lumbar spine. Orthop Clin North Am 1986;17:161-70.

50. Cantor JB, Lebwohl NH, Garvey T, Eismont FJ. Nonoperative management of stable thoracolumbar burst fractures with early ambulation and bracing. Spine (Phila Pa 1976) 1993;18:971-6.

51. Alanay A, Yazici M, Acaroglu E, Turhan E, Cila A, Surat A. Course of nonsurgical management of burst fractures with intact posterior ligamentous complex: an MRI study. Spine (Phila Pa 1976) 2004;29:242531.

52. Weinstein JN, Collalto P, Lehmann TR. Thoracolumbar "burst" fractures treated conservatively: a longterm follow-up. Spine (Phila Pa 1976) 1988;13:33-8.

53. Shuman WP, Rogers JV, Sickler ME, et al. Thoracolumbar burst fractures: CT dimensions of the spinal canal relative to postsurgical improvement. AJR Am J Roentgenol 1985;145:337-41.

54. Meves R, Avanzi O. Correlation among canal compromise, neurologic deficit, and injury severity in thoracolumbar burst fractures. Spine (Phila Pa 1976) 2006;31:2137-41.

55. Mohanty SP, Venkatram N. Does neurological recovery in thoracolumbar and lumbar burst fractures depend on the extent of canal compromise? Spinal Cord 2002;40:295-9.

56. van Middendorp JJ, Goss B, Williams RP, Schuetz M. Is there a difference between narrowing of the spinal canal and neurological deficits comparing Denis and Magerl classifications? Spinal Cord 2011;49:855.

57. Limb D, Shaw DL, Dickson RA. Neurological injury in thoracolumbar burst fractures. J Bone Joint Surg Br 1995;77:774-7.

58. Dai LY. Remodeling of the spinal canal after thoracolumbar burst fractures. Clin Orthop Relat Res 2001;(382):119-23.

59. Mumford J, Weinstein JN, Spratt KF, Goel VK. Thoracolumbar burst fractures. The clinical efficacy and outcome of nonoperative management. Spine (Phila Pa 1976) 1993;18:955-70.

60. Yi L, Jingping B, Gele J, Baoleri X, Taixiang W. Op- 
erative versus non-operative treatment for thoracolumbar burst fractures without neurological deficit. Cochrane Database Syst Rev 2006;(4):CD005079.

61. Thomas KC, Bailey CS, Dvorak MF, Kwon B, Fisher C. Comparison of operative and nonoperative treatment for thoracolumbar burst fractures in patients without neurological deficit: a systematic review. J Neurosurg Spine 2006;4:351-8.

62. Abudou M, Chen X, Kong X, Wu T. Surgical versus non-surgical treatment for thoracolumbar burst fractures without neurological deficit. Cochrane Database Syst Rev 2013;6:CD005079.

63. Gnanenthiran SR, Adie S, Harris IA. Nonoperative versus operative treatment for thoracolumbar burst fractures without neurologic deficit: a meta-analysis. Clin Orthop Relat Res 2012;470:567-77.

64. Wood K, Buttermann G, Mehbod A, Garvey T, Jhanjee R, Sechriest V. Operative compared with nonoperative treatment of a thoracolumbar burst fracture without neurological deficit. A prospective, randomized study. J Bone Joint Surg Am 2003;85:773-81.

65. Tropiano P, Huang RC, Louis CA, Poitout DG, Louis RP. Functional and radiographic outcome of thoracolumbar and lumbar burst fractures managed by closed orthopaedic reduction and casting. Spine (Phila Pa 1976) 2003;28:2459-65.

66. Wood KB, Li W, Lebl DR, Ploumis A. Management of thoracolumbar spine fractures. Spine J 2014;14:14564.

67. Kaneda K, Taneichi H, Abumi K, Hashimoto T, Satoh S, Fujiya M. Anterior decompression and stabilization with the Kaneda device for thoracolumbar burst fractures associated with neurological deficits. J Bone Joint Surg Am 1997;79:69-83.

68. Hitchon PW, Torner J, Eichholz KM, Beeler SN. Comparison of anterolateral and posterior approaches in the management of thoracolumbar burst fractures. J Neurosurg Spine 2006;5:117-25.

69. Sasso RC, Renkens K, Hanson D, Reilly T, McGuire RA Jr, Best NM. Unstable thoracolumbar burst fractures: anterior-only versus short-segment posterior fixation. J Spinal Disord Tech 2006;19:242-8.

70. Shono Y, McAfee PC, Cunningham BW. Experimental study of thoracolumbar burst fractures. A radiographic and biomechanical analysis of anterior and posterior instrumentation systems. Spine (Phila Pa 1976) $1994 ; 19: 1711-22$.
71. Gurwitz GS, Dawson JM, McNamara MJ, Federspiel CF, Spengler DM. Biomechanical analysis of three surgical approaches for lumbar burst fractures using short-segment instrumentation. Spine (Phila $\mathrm{Pa}$ 1976) 1993;18:977-82.

72. Sjostrom L, Karlstrom G, Pech P, Rauschning W. Indirect spinal canal decompression in burst fractures treated with pedicle screw instrumentation. Spine (Phila Pa 1976) 1996;21:113-23.

73. Crutcher JP Jr, Anderson PA, King HA, Montesano PX. Indirect spinal canal decompression in patients with thoracolumbar burst fractures treated by posterior distraction rods. J Spinal Disord 1991;4:39-48.

74. Gertzbein SD, Crowe PJ, Fazl M, Schwartz M, Rowed D. Canal clearance in burst fractures using the AO internal fixator. Spine (Phila Pa 1976) 1992;17:55860.

75. Kaya RA, Aydin Y. Modified transpedicular approach for the surgical treatment of severe thoracolumbar or lumbar burst fractures. Spine J 2004;4:208-17.

76. Kong W, Sun Y, Hu J, Xu J. Modified posterior decompression for the management of thoracolumbar burst fractures with canal encroachment. J Spinal Disord Tech 2010;23:302-9.

77. Carl AL, Tromanhauser SG, Roger DJ. Pedicle screw instrumentation for thoracolumbar burst fractures and fracture-dislocations. Spine (Phila Pa 1976) 1992;17:S317-24.

78. Ebelke DK, Asher MA, Neff JR, Kraker DP. Survivorship analysis of VSP spine instrumentation in the treatment of thoracolumbar and lumbar burst fractures. Spine (Phila Pa 1976) 1991;16:S428-32.

79. McLain RF, Sparling E, Benson DR. Early failure of short-segment pedicle instrumentation for thoracolumbar fractures. A preliminary report. J Bone Joint Surg Am 1993;75:162-7.

80. McNamara MJ, Stephens GC, Spengler DM. Transpedicular short-segment fusions for treatment of lumbar burst fractures. J Spinal Disord 1992;5:183-7.

81. McCormack T, Karaikovic E, Gaines RW. The load sharing classification of spine fractures. Spine (Phila Pa 1976) 1994;19:1741-4.

82. Chen C, Lv G, Xu B, Zhang X, Ma X. Posterior shortsegment instrumentation and limited segmental decompression supplemented with vertebroplasty with calcium sulphate and intermediate screws for thoracolumbar burst fractures. Eur Spine J 2014;23:1548-57. 
83. Liao JC, Fan KF, Keorochana G, Chen WJ, Chen LH. Transpedicular grafting after short-segment pedicle instrumentation for thoracolumbar burst fracture: calcium sulfate cement versus autogenous iliac bone graft. Spine (Phila Pa 1976) 2010;35:1482-8.

84. Shen YX, Zhang P, Zhao JG, et al. Pedicle screw instrumentation plus augmentation vertebroplasty using calcium sulfate for thoracolumbar burst fractures without neurologic deficits. Orthop Surg 2011;3:1-6.

85. Rahamimov N, Mulla H, Shani A, Freiman S. Percutaneous augmented instrumentation of unstable thoracolumbar burst fractures. Eur Spine J 2012;21:8504.

86. Korovessis P, Repantis T, Petsinis G, Iliopoulos P, Hadjipavlou A. Direct reduction of thoracolumbar burst fractures by means of balloon kyphoplasty with calcium phosphate and stabilization with pediclescrew instrumentation and fusion. Spine (Phila Pa 1976) 2008;33:E100-8.

87. Marco RA, Kushwaha VP. Thoracolumbar burst fractures treated with posterior decompression and pedicle screw instrumentation supplemented with balloon-assisted vertebroplasty and calcium phosphate reconstruction. J Bone Joint Surg Am 2009;91:20-8.

88. Verlaan JJ, Dhert WJ, Verbout AJ, Oner FC. Balloon vertebroplasty in combination with pedicle screw instrumentation: a novel technique to treat thoracic and lumbar burst fractures. Spine (Phila Pa 1976) 2005;30:E73-9.

89. Alanay A, Acaroglu E, Yazici M, Oznur A, Surat A. Short-segment pedicle instrumentation of thoracolumbar burst fractures: does transpedicular intracorporeal grafting prevent early failure? Spine (Phila $\mathrm{Pa}$ 1976) 2001;26:213-7.

90. Knop C, Fabian HF, Bastian L, Blauth M. Late results of thoracolumbar fractures after posterior instrumentation and transpedicular bone grafting. Spine (Phila Pa 1976) 2001;26:88-99.

91. Toyone T, Tanaka T, Kato D, Kaneyama R, Otsuka M. The treatment of acute thoracolumbar burst fractures with transpedicular intracorporeal hydroxyapatite grafting following indirect reduction and pedicle screw fixation: a prospective study. Spine (Phila Pa 1976) 2006;31:E208-14.

92. Toyone T, Ozawa T, Inada K, et al. Short-segment fixation without fusion for thoracolumbar burst fractures with neurological deficit can preserve thoraco lumbar motion without resulting in post-traumatic disc degeneration: a 10-year follow-up study. Spine (Phila Pa 1976) 2013;38:1482-90.

93. Guven O, Kocaoglu B, Bezer M, Aydin N, Nalbantoglu $\mathrm{U}$. The use of screw at the fracture level in the treatment of thoracolumbar burst fractures. J Spinal Disord Tech 2009;22:417-21.

94. Mahar A, Kim C, Wedemeyer M, et al. Shortsegment fixation of lumbar burst fractures using pedicle fixation at the level of the fracture. Spine (Phila Pa 1976) 2007;32:1503-7.

95. Dai LY, Jiang LS, Jiang SD. Posterior short-segment fixation with or without fusion for thoracolumbar burst fractures. a five to seven-year prospective randomized study. J Bone Joint Surg Am 2009;91:103341.

96. Ni WF, Huang YX, Chi YL, et al. Percutaneous pedicle screw fixation for neurologic intact thoracolumbar burst fractures. J Spinal Disord Tech 2010; 23:530-7.

97. Alpantaki K, Bano A, Pasku D, et al. Thoracolumbar burst fractures: a systematic review of management. Orthopedics 2010;33:422-9.

98. Wilke HJ, Kemmerich V, Claes LE, Arand M. Combined anteroposterior spinal fixation provides superior stabilisation to a single anterior or posterior procedure. J Bone Joint Surg Br 2001;83:609-17.

99. Danisa OA, Shaffrey CI, Jane JA, et al. Surgical approaches for the correction of unstable thoracolumbar burst fractures: a retrospective analysis of treatment outcomes. J Neurosurg 1995;83:977-83.

100. Schmid R, Krappinger D, Blauth M, Kathrein A. Mid-term results of PLIF/TLIF in trauma. Eur Spine J 2011;20:395-402.

101. Schmid R, Krappinger D, Seykora P, Blauth M, Kathrein A. PLIF in thoracolumbar trauma: technique and radiological results. Eur Spine J 2010;19: 1079-86.

102. Anderson PA, Rivara FP, Maier RV, Drake C. The epidemiology of seatbelt-associated injuries. J Trauma 1991;31:60-7.

103. Chapman JR, Agel J, Jurkovich GJ, Bellabarba C. Thoracolumbar flexion-distraction injuries: associated morbidity and neurological outcomes. Spine (Phila Pa 1976) 2008;33:648-57.

104. Liu YJ, Chang MC, Wang ST, Yu WK, Liu CL, Chen TH. Flexion-distraction injury of the thoracolum- 
bar spine. Injury 2003;34:920-3.

105. Kim YM, Kim DS, Choi ES, et al. Nonfusion method in thoracolumbar and lumbar spinal fractures. Spine (Phila Pa 1976) 2011;36:170-6.

106. Grossbach AJ, Dahdaleh NS, Abel TJ, Woods GD, Dlouhy BJ, Hitchon PW. Flexion-distraction injuries of the thoracolumbar spine: open fusion versus percutaneous pedicle screw fixation. Neurosurg Fo- cus 2013;35:E2.

107. Herkowitz HN, Garfin SR, Eismont FJ, Bell GR, Balderston RA. Rothman-Simeone the spine: expert consult. London: Elsevier Health Sciences; 2011.

108. Hao D, Wang W, Duan K, et al. Two-year follow-up evaluation of surgical treatment for thoracolumbar fracture-dislocation. Spine (Phila Pa 1976) 2014;39: E1284-90. 